\title{
Antibacterial Bioactive Glass, S53P4, for Chronic Bone Infections - A Multinational Study
}

\section{Lindfors, Nina}

Springer International Publishing AG

2017

Lindfors , N , Geurts , J , Drago , L , Arts , J J , Juutilainen , V , Hyvönen , P , Suda , A J , Domenico , A , Artiaco , S , Alizadeh , C , Brychcy , A, Bialecki , J \& Romano , C L 2017 , Antibacterial Bioactive Glass, S53P4, for Chronic Bone Infections - A Multinational Study . in L Drago (ed.) , MODERN APPROACH TO BIOFILM-RELATED ORTHOPAEDIC IMPLANT INFECTIONS: ADVANCES IN MICROBIOLOGY, INFECTIOUS DISEASES AND PUBLIC HEALTH, VOL 5 . Advances in Experimental Medicine and Biology, vol. 971 , Springer International Publishing AG , pp. 81-92 .https://doi.org/10.1007/5584_2016_156

http://hdl.handle.net/10138/252437

https://doi.org/10.1007/5584_2016_156

publishedVersion

Downloaded from Helda, University of Helsinki institutional repository.

This is an electronic reprint of the original article.

This reprint may differ from the original in pagination and typographic detail.

Please cite the original version. 


\title{
ERRATUM
}

Adv Exp Med Biol - Advances in Microbiology, Infectious Diseases and Public Health DOI 10.1007/5584_2017_13

(C) Springer International Publishing Switzerland 2017

\section{Antibacterial Bioactive Glass, S53P4, for Chronic Bone Infections - A Multinational Study}

\author{
Nina Lindfors, Jan Geurts, Lorenzo Drago, J.J. Arts, \\ Vesa Juutilainen, Pekka Hyvönen, Arnold J. Suda, \\ Aloj Domenico, Stefano Artiaco, Chingiz Alizadeh, \\ Adrian Brychcy, Jertzy Bialecki, and Carlo L. Romanò
}

The original chapter was corrected. Please find below the summary of the corrections made:

Author's name "Arnold J. Suda" was misspelt as Arnold Suda which has been corrected in this version.

Author's name "Carlo L. Romanò" was misspelt as Carlo Romano which has been corrected in this version.

Affiliations of authors were missing in the previous version. The affiliations have now been included as listed below.

Lindfors $\mathrm{NC}^{1}$, Geurts $\mathrm{J}^{2}$, Drago $\mathrm{L}^{3}$, Arts $\mathrm{JJ}^{4}$, Juutilainen $\mathrm{V}^{1}$, Hyvönen $\mathrm{P}^{5}$, Suda $\mathrm{AJ}^{6}$, Aloj $\mathrm{D}^{7}$, Artiaco $\mathrm{S}^{7}$, Alizadeh $\mathrm{Ch}^{8}$, Brychcy $\mathrm{A}^{9}$, Bialecki $\mathrm{J}^{9}$, Romanò $\mathrm{CL}^{10}$

1. Department of Orthopaedic and Plastic Surgery, Helsinki University Central Hospital, Helsinki University, Helsinki, Finland.

2. Department of Orthopaedic Surgery, Research School CAPHRI, Maastricht University Medical Centre, Maastricht, The Netherlands

3. Laboratory of Clinical Chemistry and Microbiology, I.R.C.C.S. Galeazzi Orthopaedic Institute, Milan, Italy

4. Department of Orthopaedic Surgery, Research School CAPHRI, Maastricht University Medical Centre, Maastricht and Orthopaedic Biomechanics Group, Department of Biomedical Engineering, Eindhoven University of Technology (TU/e), The Netherlands

The updated online version of the original chapter can be found under DOI 10.1007/5584_2016_156 
5. Department of Orthopaedic and Traumatology, Oulu University Hospital, Oulu, Finland.

6. Department for Septic Surgery, BG Trauma Center Ludwigshafen, Ludwigshafen, Germany

7. I Orthopaedic Clinic, University of Turin, Orthopaedic and Trauma Center - CTO Hospital, Turin, Italy

8. Azerbaijan Scientific Research Institute of Traumatology and Orthopaedics, Baku, Azerbaijan

9. Department of Bone and Joint Infections, Orthopedic Clinic of Postgraduate Medical Education Centre, Otwock, Poland

10. Center for Reconstructive Surgery of Osteoarticular Infections (CRIO), I.R.C.C.S. Galeazzi Orthopaedic Institute, Milan, Italy

The legends of Tables 1,2, and 4 are divided into two parts one up and one down the Table. This is also not according to Springer Nature guidelines. This has also been corrected. 